\section{Boosting Your Brain, Part 1: The Couch Potato}

\author{
M. Castillo, Editor-in-Chief
}

T he issue of failing memory worries us all, particularly as we get older. The treacherous nature of memory and its distortions caused by advancing age have been dealt with in several recent bestselling books from Julian Barnes' The Sense of an Ending ${ }^{1}$ to Patrick Modiano's L'Horizon. ${ }^{2}$ In both books, individuals in their late 50 s or 60 s attempt to reconstruct past events in different ways and with different results. Professor William Miller made light of his declining mental abilities in his book Losing $I t{ }^{3}$ which he subtitled: "In which an aging professor laments his shrinking brain which he flatters himself formerly did him noble service." Is there anything that we can do to keep from "losing it"? Can we really be "older and wiser"? In this first part, I discuss (presumed) ways to exercise your brain while avoiding exercising your body.

Dr Lawrence Katz, a former Duke University professor of neurobiology, is said to be the father of "neurobics" (yes, meaning aerobics for your neurons). Aerobics means "living in air" or, more scientifically, being able to supply enough oxygen to support increased aerobic cellular metabolism during exercise. ${ }^{4} \mathrm{Al}-$ though it is possible that we do lose some neurons with age, the "no new neuron" theory that stated that as we get older our neurons die and are not replaced has been disproved. Brain stem cells from the hippocampi and subventricular zones constantly multiply and repopulate the cortex throughout our lives. It is possible that age-related mental decline is due to a malfunction of dendrites and synapses, but the good news is that older as well as new neurons can easily sprout new dendrites. The number of oligodendrocytes also decreases with age, leading to myelin fragmentation, decreased number of myelinated fibers, and ultimately loss of axons. ${ }^{5}$ Diffusion tensor imaging has shown that myelin achieves its greatest degree of complexity during the fifth decade of life, so it is not surprising that many of us feel that middle age is when we have been smartest. DTI has also demonstrated stronger connectivity in regions associated with better executive function. ${ }^{6}$ Some think that by using DTI to identify weak connections, we should be able to design specific brain exercises aimed at strengthening these regions.

Even Aristotle knew that practice was helpful in maintaining a healthy brain. ${ }^{7}$ Traditional brain exercises include puzzles and memory jogging. Reading and even playing bingo are said to be beneficial, and maybe that is why both are popular in retirement homes. Among the many Web sites dedicated to brain exercises, Happy Neuron ${ }^{8}$ lets you tailor several games according to your age, sex, and education level and then makes money by attempting to sell you "adult brain-training products" by using descriptions reminiscent of those used by a different a type of "adult" industry. This Web site claims to improve your brain by $16 \%$ (whatever that means).

http://dx.doi.org/10.3174/ajnr.A3189
In a study published in 2002, cognitive training was effective and durable in improving cognitive function. ${ }^{9}$ The authors reported that the benefits of training basically erased the expected mental decline during 7- and 14-year periods. This is important because prior studies had shown that the effects of mental calisthenics tend to last only 2 years. What the authors do not clearly explain is why there was no functional brain decline in the control group as would have been expected.

Thus, it is not surprising that many scientists accept the beneficial effects of brain training but warn us that these are only moderate. Additionally, you get better at what you trained for and nothing else. A recent article in Nature ${ }^{10}$ reported that more than 11,400 subjects were trained several times per week in tasks designed to improve reasoning, memory, planning, and attention. Although improvements were noted for these specific tasks, the benefits could not be transferred to other untrained tasks, even if they were cognitively closely related. This observation is akin to my children telling me that computer games make them smarter. These games make them better at playing the games but nothing else.

Most of these brain exercises do not result in what is called long-term potentiation - the potentiation is present only while you do them regularly. The idea behind long-term potentiation is that brain exercises lead to production of neurotrophins, such as brain-derived neurotrophic factor, which stimulates dendritic sprouting and actually physically changes the brain. Neurotrophins, however, only result in neuronal branching when those same neurons are being constantly stimulated. Analogous to a muscle, if you stop your exercises, that part of the brain turns flabby. Extensive long-term repeated experiences may induce changes in brain morphology due to neuroplasticity. London taxi drivers have increased gray matter and hippocampal volumes. ${ }^{11}$ The longer they drive, the bigger these regions get. I wonder if these will regress in size if drivers start using a Global Positioning System. Learning music, as an adult or a child, improves verbal and working memory as well as attention and is also said to change the shape of the brain. ${ }^{12}$

Couch potatoes may be too lazy even to exercise mentally; so, what could be better than improving your brain by just swallowing a pill? The use of methylphenidate (Ritalin) as a neuroenhancer is widespread in American high schools and on college campuses (this is not the case in Europe and Latin America). Students who do not have documented attention deficit disorders take it to cram for examinations. By increasing brain dopamine, they feel more alert, focused, interested, and motivated. Amphetamines in different forms stimulate the brain and are also widely used on university campuses. Adderall is one of these medications and is only legal in the United States and Canada (so again, not used for that purpose elsewhere). Students report a 2-letter improvement in their grades when taking these drugs. ${ }^{13}$ On some campuses, up to $35 \%$ of students regularly take these pills. ${ }^{14}$ Other "smart drugs" include phosphatidyl serine (said to activate cellto-cell communication) and vinpocetine (increases blood flow to the brain and eyes); others that should improve memory and boost intelligence are now being designed. The list of acute and 
chronic complications from using any of these drugs is too long to recount here, but pharmaceutical companies will continue to make and sell them rather indiscriminately because they are a huge business. In 2010, more than US $\$ 470$ million of Ritalin was sold, and because we want to make all medications cheaper and more available, the company Actavis (Elizabeth, New Jersey) this year launched its generic and less expensive equivalent. ${ }^{15} \mathrm{Com}-$ monly available in nearly all supermarkets is ginkgo biloba, which may moderately improve cognition particularly in aging individuals and patients with Alzheimer disease. This extract from plant leaves acts by increasing cerebral blood flow, and a study done at Johns Hopkins by using perfusion MR imaging showed that cerebral blood flow was mildly and globally increased in elderly individuals who took that supplement twice per day. ${ }^{16}$ Additionally, it has been given to patients with Down syndrome and early-onset Alzheimer disease with positive results. ${ }^{17}$

If all of the above seems too time-consuming, too expensive, or too risky, you may want to try neurobics. Neurobics requires only that you do 2 things: experience the unexpected and use all of your senses every day. ${ }^{18}$ Dr Katz's method has been extremely popular, and his book has been reprinted 25 times and translated into 24 languages. His coauthor, Mr Manning Rubin, is a commercial writer who runs an advertising company and has worked for some of the biggest marketing organizations in the world, so he knows a bit about product placement; but in all fairness to the book, Dr Katz was the real thing (he died in 2005 from melanoma). A graduate of the University of Chicago and the California Institute of Technology, he went on to become faculty at Duke University and published many articles in peer-reviewed journals. Because neurobics can be incorporated into any of our daily activities, it sounds initially attractive, but it seems that like anything else, when you look carefully into it, it is a bit more complicated. Here are some of the recommended activities (my comments in parentheses):

1) Shower with your eyes closed. (The book clearly warns you about balance issues, common as we get older, and water that may be hot if you are not looking at the temperature handle.)

2) Get dressed with your eyes closed. (Tried it last week and ended up putting on socks that were the wrong color.)

3) Brushing roulette, meaning brush your teeth or hair with your nondominant hand. (Be careful about hurting your gums or poking an eye.)

4) Listen to specific music while smelling something particular. (This requires a bit of planning, and I have not tried it yet because it seems too complicated and I cannot decide which smell goes well with Orff's Carmina Burana.)

5) Take your family to work with you. (I imagine that the mental exercise kicks in when trying to explain to them how susceptibility-weighted imaging or iterative reconstruction works. Beware: this can be a Health Insurance Portability and Accountability Act violation!)

6) Wear ear plugs when you sit down for a meal with your family. (I think it is the effort of lip reading that exercises your mind. Ask your spouse before doing this to avoid conflicts at home.)

7) Turn your computer monitor upside down. (When I was a resident, a very senior and very smart attending used to read the chest radiographs upside down. He was doing neurobics without even knowing it!)

8) Shop at the farmers' market instead of the Big Box supermarket. (You get to talk to real folks, eat healthier, and support your local economy. Not a bad idea!)

The list of somewhat wacky ideas goes on and on (eg, create a sensory symphony in the bath, start watching Sesame Street again, and so forth). Dr Katz also reminds us that sex is the ultimate brain workout; but because it can also be a physical workout and this Perspectives does not deal with physical exercise, I will comment on it next month in Part 2. The book, Keep Your Brain Alive, contains detailed chapters on neurobics during your morning and afternoon commutes and neurobics while at work, at the market, at mealtimes, and at leisure. In reality, most of its recommendations involve variations on activities that we get too lazy to do as time goes by.

If you are still too lazy to do any of the above, how about just breathing? Oxygen appears to enhance memory. Higher blood oxygen saturation increases the heart rate, and both correlate with improved brain performance. In one study, subjects who inhaled oxygen 60 seconds before attempting to memorize a word list outperformed those who did not. ${ }^{19}$ Oxygen cannot be given in advance; it has to be inhaled just before the task, suggesting it is increased blood oxygen saturation that plays a role in memory consolidation. Every time I lecture, I look at my presentation and try to memorize all of its slides so that I can "bridge" them while speaking. Because I do not carry an oxygen tank with me, just recently I tried hyperventilating before a lecture, and the results were that I felt dizzy and shaky, my hands were tingling, and I ended up giving a terrible lecture. There are better ways to improve your memory, albeit involving some work and discipline, and my next Perspectives will deal with these.

\section{REFERENCES}

1. Barnes J. The Sense of an Ending. New York: Knopf; 2011

2. Modiano P. L'Horizon. Paris, France: Editions Gallimard; 2010

3. Miller W. Losing It. New Haven, Connecticut: Yale University Press; 2011

4. Aeorobic exercise. Wikipedia. http://en.wikipedia.org/wiki/Aerobic_exercise. Accessed April 16, 2012

5. Marner L, Nyengaard JR, Tang Y, et al. Marked loss of myelinated nerve fibers in the human brain with age. J Comp Neurol 2003;462:144-52

6. Wen W, Zhu W, He Y, et al. Discrete neuroanatomical networks are associated with specific cognitive abilities in old age. J Neuroscience 2011;31:1204-12

7. Aristotle. De memoria et reminiscentia. http://etext.lib.virginia.edu/ toc/modeng/public/AriMemo.html. Accessed April 16, 2012

8. Happy Neuron: 100,000,000 games played. Brain fitness for life. http://www.happy-neuron.com. Accessed April 16, 2012

9. Ball K, Berch DB, Helmers KF, et al. Effects of cognitive training with older adults: a randomized controlled trial. JAMA 2002;28:2271-81

10. Owen AM, Hampshire A, Grahn J, et al. Putting brain training to the test. Nature 2010;465:775-79

11. Maguire EA, Woollett K, Spiers HJ. London taxi drivers and bus drivers: a structural MRI and neuropsychological analysis. Hippocampus 2006;16:1091-101

12. Memory improvement. Wikipedia. http://en.wikipedia.org/wiki/ Memory_improvement. Accessed April 16, 2012

13. Popping pills a popular way to boost brain power. http:// 
www.cbsnews.com/2100-18560_162-6422159.html?pageNum = 2\&tag = contentMain;contentBody. Accessed April 16, 2012

14. Talbot M. Can a daily pill really boost your brain power? 60 Minutes. http://www.guardian.co.uk/science/2009/sep/20/neuroenhancers-usbrain-power-drugs. Accessed April 16, 2012

15. Ritalin. http://www.evaluatepharma.com/Universal/View.aspx? type $=$ Entity\&entityType $=$ Product $\& i d=10818 \& 1$ Type $=\bmod$ Data\&componentID = 1002. Accessed April 16, 2012

16. Masahyekh A, Pham DL, Yousem DM, et al. Effects of ginkgo biloba on cerebral blood flow assessed by quantitative MR perfusion: a pilot study. Neuroradiology 2011;53:185-91

17. Buckely F, Sacks B. Drug treatment improves memory in mice. http:// www.down-syndrome.org/updates/2037. Accessed April 16, 2012

18. Katz LC, Rubin M. Keep Your Brain Alive. New York: Workman Publishing Company; 1999

19. Chung SC, Lim DW. Changes in memory performance, heart rate and blood oxygen saturation due to $30 \%$ oxygen administration. Int J Neurosci 2008;114:593-606

\section{$\overline{\text { EDITORIAL }}$}

\section{Radiation Risk Due to Shunted Hydrocephalus and the Role of MR Imaging-Safe Programmable Valves}

\author{
S. Krishnamurthy \\ B. Schmidt \\ M.D. Tichenor
}

D iagnostic radiology is a double-edged sword: While providing critical information that forms the basis of treatment, it adds to the risk associated with cumulative radiation given to the patient. Shunted hydrocephalus exemplifies this conundrum. Hydrocephalus is a common neurosurgical condition that affects individuals of all ages, and the most common method for managing hydrocephalus is the surgical implantation of a shunt system to divert the flow of CSF from the ventricles. ${ }^{1,2}$ More than 125,000 shunts are implanted every year in the United States at a cost of US $\$ 2$ billion. ${ }^{3}$ Nearly half of this cost is associated with shunt revisions. ${ }^{4}$

Although most cases of hydrocephalus have clinical improvement with the insertion of a shunt, it is rare for the device to last a lifetime without complications. ${ }^{2}$ Shunts can be obstructed and infected, and tubing may get disrupted, resulting in recurrence of symptoms. In 1 study, the shunt failure rate in children was reported to be $31 \%$ within the first year and $4.5 \%$ per year thereafter; the failure rate in adults was found to be comparable with that in children. ${ }^{5}$ In another study, the overall shunt survival in pediatric patients was $62 \%$ at 1 year, $52 \%$ at 2 years, $46 \%$ at 3 years, and $41 \%$ at 4 years. ${ }^{6}$ In a third study, the probability of shunt malfunction after 12 years was $81 \%{ }^{7}$ The high incidence of device problems and the potential for serious consequences as a result, combined with patients who have cognitive problems expressing their symptoms, predicts frequent visits to emergency departments and urgent care centers.

The integrity of the tubing is checked by a series of $\mathrm{x}$-rays of the

http://dx.doi.org/10.3174/ajnr.A3334 head, chest, and abdomen; the size of the ventricles is assessed by $\mathrm{CT}$ of the head. ${ }^{8} \mathrm{CT}$ is often the preferred technique because of its wide accessibility, ease of use, and brief imaging period. Initial scans focus on finding abnormal pathologies, while subsequent scans are oriented toward assessment of the shunt, determination of stability of ventricular volume, and identification of related complications. This need for confirming the suspicion of a shunt malfunction by diagnostic radiology increases the risk for longterm effects of ionizing radiation. ${ }^{9,10}$ The effective doses for $\mathrm{x}$-rays are 0.1 (skull), 0.1 (chest), and 0.7 (abdomen) $\mathrm{mSv}$, respectively; and for CT of the head, it is $2.0 \mathrm{mSv} .{ }^{11}$ In other words, a visit to the emergency department will result in nearly the same amount of radiation that any healthy individual gets from background radiation (estimated at $3 \mathrm{mSv}$ ) during a year. ${ }^{11}$ Despite this diligence in managing shunt problems, 2 of 3 patients who are investigated are not found to have shunt malfunction. ${ }^{12}$

Excessive exposure to radiation is of greater concern in children because rapidly dividing cells in children are more radiosensitive than those in adults. ${ }^{13,14}$ Additionally, a longer lifetime for children allows the manifestation of radiation injuries, which have a long latency period before they become apparent in patients. ${ }^{13}$ The National Council on Radiation Protection and Measurements estimated that during the past 2 decades the total exposure of the US population to ionizing radiation has nearly doubled. ${ }^{15}$ Studies have shown that patients most prone to harm from diagnostic radiation are children and young adults ${ }^{16}$; individuals with medical conditions sensitive to radiation, such as diabetes mellitus and hyperthyroidism ${ }^{17}$ (which are possible risk factors associated with normal pressure hydrocephalus $)^{18}$; and individuals receiving multiple doses with time. ${ }^{19}$ From the 72 million CT scans performed in the United States during 2007, 1 study estimated that 29,000 future cancers and 14,500 deaths could result from radiation (assuming the cancer incidence to be $0.04 \%) .{ }^{20,21}$ The radiation doses that an organ receives from a typical CT study involving 2-3 scans are in the range of direct statistical significance for increased cancer risk. ${ }^{14}$ There are significant associations between the estimated radiation doses provided by $\mathrm{CT}$ scans to red bone marrow and brain and subsequent incidence of leukemia and brain tumors. Assuming typical doses for scans done after 2001 in children aged younger than 15 years, cumulative ionizing radiation doses from 2-3 head CTs could almost triple the risk of brain tumors and 5-10 head CTs could triple the risk of leukemia. ${ }^{22}$ In 2002, the International Commission on Radiologic Protection stated, "The absorbed dose to tissue from CT can often approach or exceed the levels known to increase the probability of cancer." ${ }^{23}$ Although some studies may rely on unproven scientific assumptions or have not finished collecting data, they illustrate an important consideration for maintaining diagnostic radiation exposure at a minimum.

The use of MR images can reduce the amount of ionizing radiation exposure to patients with shunts, as opposed to the use of $\mathrm{x}$-rays and CT scans. Reducing radiation delivered to patients could lessen the incidences of long-term effects of radiation, most notably cancer, because the risk of all solid cancers increases linearly with increasing radiation doses up to $2.5 \mathrm{~Sv} .{ }^{14}$ Fast TSE T2 sequences are commonly used in rapid brain MR imaging. ${ }^{24-28}$ Despite their utility, at least 2 limitations have been described. 